Gibson, Stephen ORCID:

https://orcid.org/0000-0002-5648-7669 and Booth, Rachael (2017) 'An Australian-style points system': Individualizing immigration in radical right discourse in the 2015 UK General Election campaign. Peace \& Conflict: Journal of Peace Psychology, 24 (4). pp. 389-397.

Downloaded from: http://ray.yorksj.ac.uk/id/eprint/2276/

The version presented here may differ from the published version or version of record. If you intend to cite from the work you are advised to consult the publisher's version: http://psycnet.apa.org/psycinfo/2017-29684-001/

Research at York St John (RaY) is an institutional repository. It supports the principles of open access by making the research outputs of the University available in digital form. Copyright of the items stored in RaY reside with the authors and/or other copyright owners. Users may access full text items free of charge, and may download a copy for private study or non-commercial research. For further reuse terms, see licence terms governing individual outputs. Institutional Repository Policy Statement

\title{
RaY
}

Research at the University of York St John

For more information please contact RaY at ray@yorksj.ac.uk 
'An Australian-style points system': Individualizing immigration in radical right discourse in the 2015 UK General Election campaign.

\author{
Stephen Gibson \& Rachael Booth \\ York St John University
}

Author Note

Stephen Gibson, School of Psychological \& Social Sciences, York St John

University; Rachael Booth, School of Psychological \& Social Sciences, York St John University.

This research was supported by grants from the British Psychological Society and York St John University.

Correspondence concerning this article should be addressed to Stephen Gibson, School of Psychological \& Social Sciences, York St John University, Lord Mayor's Walk, York, YO31 7EX, UK. E-mail: s.gibson@yorksj.ac.uk 


\begin{abstract}
Analyses of racist discourse have often involved data from contexts concerning issues of human mobility. A great deal of this literature points to the extent to which people draw on the tropes of liberalismin order to justify social exclusion, and in particular to warrant negative evaluations of outgroups. Using media data from political debates involving the radical right-wing United Kingdom Independence Party (UKIP) in the UK General Election campaign of 2015, the present paper highlights a different rhetorical strategy by which exclusion can be warranted by speakers arguing for a reduction in immigration. This novel strategy explicitly avoids any negative characterisation of outgroups, and instead advocates the individualization of immigration decisions. This is exemplified in UKIP's policy of basing the UK's approach to immigration on an 'Australian style points-based system'. This was invoked by UKIP representatives in the debates as a straightforward 'off-the-shelf' system that would enable the UK to 'take back control' of immigration, whilst ensuring that immigration decisions were based on individual merit rather than on group membership. As such, the points system could also be invoked specifically to anticipate and counter accusations of racism and/or xenophobia. The findings are discussed in relation to the tacit ideological assumptions underpinning UKIP's policy, specifically around psychologisation, the reliance on an acultural version of Australia, and the tacit use of categorical accounting. Keywords: discourse, immigration, prejudice, racism, UKIP
\end{abstract}


'An Australian-style points system': Individualizing immigration in radical right discourse in the 2015 UK General Election campaign.

A great deal of research on immigration discourse has focussed on the way in which those arguing in favour of restrictions on immigration seek to 'dodge the identity of prejudice' (Wetherell \& Potter, 1992, p. 211). Speakers orient to the opprobrium attached to anything that might be construed as indicative of racism, xenophobia or nationalism, and work to present their arguments as based on rational, objective criteria. In this respect, speakers orient to liberal values of tolerance and reason, whilst simultaneously justifying exclusion. Nevertheless, tacit assumptions about 'the other', and about the appropriate way of organising human societies, remain. Indeed, the very idea of immigration assumes what Billig (1995) referred to as a banal nationalist frame of reference in which the inevitability and naturalness of the nation-state is taken for granted. In this paper, we explore these issues in the context of the recent rise of right-wing populism, and focus in particular on the UK context, in which the United Kingdom Independence Party (UKIP) has been prominent in recent political developments, culminating in the referendum vote for the UK to leave the European Union (EU) in 2016.

\section{The language of 'race' and racism}

Research on the discourse of 'race' and racism has drawn attention to a range of rhetorical strategies through which speakers seek to manage their identity. In an influential review, Augoustinos and Every (2007) summarised five strategies commonly used when issues of 'race' and racism become live. First, speakers explicitly deny racism. Such a strategy is well documented (e.g. van Dijk, 1992), and notably displays a speaker's orientation to the possibility that what they are saying may be heard as indicative of racism. 
Second, speakers ground their views in external reality, attending to norms of rationality. For instance, to avoid the implication that their views may be the product of ignorance, speakers can construct their position as having been arrived at as a result of living in close proximity with 'the other'. Third, speakers present the ingroup in positive terms and outgroups in negative terms. Thus, 'we' may be constructed as welcoming and hospitable, but 'they' abuse our hospitality. Fourth, through a process of discursive deracialisation, speakers' negative portrayals of outgroups are constructed so as to minimise the relevance of 'race'. Alternative categories of nation and culture may instead be emphasised, or alternative grounds for criticising outgroups (e.g. economics) may be mobilised. Fifth, speakers draw on the tropes of liberalismin order to argue for fundamentally illiberal policies, such as exclusion and discrimination. Appeals to liberal values such as inclusion, fairness, equality and tolerance can all be used to argue for the exclusion of 'the other'.

In many respects Augoustinos and Every's final category concerning appeals to liberal values is the key to understanding the way in which exclusion is enacted, and underpins the other categories they identified. Billig (e.g. 1991) has argued that the tropes and dilemmas of liberal ideology can be found in much contemporary western 'commonsense' thinking. Much of the work on discourses of 'race' and racism has drawn on data from contexts which concern the issue of human mobility, and in this respect has explored the way in which tensions - often implicit - can be detected between liberal values of rationality and tolerance, and (banal) nationalist assumptions concerning the primacy of the nation state, and the 'natural' belonging of a people in a homeland.

In order to extend this line of work, the present analysis explores a novel rhetorical strategy through which speakers from the populist right-wing United Kingdom Independence Party (UKIP) sought to make their case for reducing immigration in such a way as to anticipate and deflect the implication that they, or their party's policy, may be racist or 
xenophobic. Augoustinos and Every's (2007, p. 124) review identified a range of 'pervasive discursive repertoires and rhetorical devices that are combined flexibly by majority group members to justify negative evaluations of minority out-groups.' In contrast, rather than justifying exclusion of immigrants through explicit category construction, the strategy that is the focus of the present analysis involves the individualization of decisions concerning who is and who is not allowed to immigrate. In particular, it is suggested that while UKIP's strategy reflects several well-established themes identified in previous work on discourses of 'race' and immigration, the specific way in which the party's representatives mobilise the policy are reflective of a relatively novel approach to the use of liberal individualist values for the purposes of social exclusion, and one that is not limited to the UK context. Moreover, whilst overt category work is largely absent, more subtle tacit distinctions between 'us' and 'them' are maintained.

\section{The research context}

The present study focuses on data from the 2015 UK General Election campaign, and in particular on the discourse of UKIP. The party had its best ever General Election results in 2015, coming third in the popular vote with 3.88 million votes, a $12.6 \%$ share (Cowley \& Kavanagh, 2015). While this only translated into a single seat in the House of Commons, the effect on the result was arguably vital for two reasons: First, UKIP's policy on reducing immigration enabled it to take votes from Labour in northern England; second, concern about losing votes to UKIP led to the Conservative Party making a manifesto commitment to holding a referendum on membership of the European Union (EU) (Cowley \& Kavanagh, 2016), which ultimately led to the decision to leave the EU when the referendum was held in June 2016. Thus, while it has never been a major parliamentary force, UKIP has undoubtedly had a major effect on British politics, and - assuming that the referendum result is enacted - 
has fulfilled its raison d'être, having been founded in 1993 as a single-issue party dedicated to withdrawing the UK from the EU (Ford \& Goodwin, 2014).

The rise of UKIP in recent years can be traced in no small part to the party's position on immigration. The party's key goal of UK withdrawal from the EU was not high on the list of voters' priorities for most of UKIP's existence (Ford \& Goodwin, 2014). Its linking of immigration with EU membership has been an important step in persuading voters who may not otherwise have been overly concerned about EU membership, but who were concerned about immigration, that the real problem was the EU (Ford \& Goodwin, 2014). This has been accomplished via strategies designed to inoculate the party from accusations of racist, right-wing extremism, whilst simultaneously criticising mainstream politicians as aloof from 'ordinary' people, and contemptuous of their concerns. UKIP's specific policy on immigration has been to '[i]ntroduce an Australian-style points based system to manage the number and skills of people coming into the country' (UKIP, 2015, p. 11). The present paper explores how this policy was articulated in the build-up to the 2015 election, and focuses in particular on how the characterization of the policy as involving an 'Australian-style points system' functioned to anticipate and respond to accusations of racism, xenophobia, or otherwise prejudicial sentiment.

\section{Method}

\section{Data}

The data for this analysis were drawn from a broader project that aimed to explore immigration discourse in political debates broadcast on television and radio in the $2015 \mathrm{UK}$ General Election campaign. The bulk of the dataset consisted of episodes of the British Broadcasting Corporation's (BBC) flagship televised political debate programme, Question Time, and its radio counterpart, Any Questions, as well as the official election debate 
programmes. In addition, two high-profile one-on-one interviews with UKIP's leader, Nigel Farage, were included in the dataset. These were broadcast as special editions of The Late Debate, broadcast by the Independent Television(ITV) network, and the BBC's Newsnight. The overall dataset consisted of a total of 17 separate programmes, spanning the time period from 26 February to 1 May 2015. Recordings of the programmes were accessed via the BBC website (for Any Questions) and YouTube (for all other programmes). Twelve of these featured representatives of UKIP, and it is on this subset that the present analysis was performed. The data were transcribed by the second author using a simplified form of Jeffersonian transcription notation (see Appendix for a list of conventions used).

\section{Analytic Procedure}

Analysis proceeded in accordance with the methodological principles of Discursive Psychology (Potter, 2012). This is a social constructionist approach that emphasises the way in which discourse is constructed in order to perform particular functions that are situated in specific social contexts. The dataset was first read repeatedly to identify potential phenomena of interest. One such phenomenon was the use of the rhetorical commonplace 'an Australian-style points system', which was invoked repeatedly by speakers representing UKIP. After deciding that it would be worth exploring in more detail how this phrase was used, the next stage of analysis involved the identification of all occasions on which it was invoked. These instances were then extracted into a separate file to allow for comparison across cases. At this stage, we erred on the side of over-inclusion to ensure that apparently partial or unclear uses of the phrase were collated (Potter \& Wetherell, 1987).

Once we had a collection of instances in which the points system was invoked, we undertook detailed analysis on these stretches of talk. In order to ensure that our developing analysis did not divorce data from its surrounding discursive context, the material in the 
collection was read in the context of the broader debate in which they occurred at various points during the analysis, up to and including writing up. Detailed analysis focussed on the specific discursive devices used to construct UKIP's position, as well as the way that others in the debates challenged UKIP speakers in ways that occasioned the invocation of the points system.

\section{Analysis}

Analysis identified that the phrase, or close variations of it, were used by UKIP speakers in 8 debates. The present analysis highlights two features of how the "points system' was constructed and used: 1) It was used by UKIP speakers in order to set out a position on immigration policy that would address what they constructed as the key problem, namely an 'open door' approach to immigration that had led to a loss of control over the number of immigrants coming to the UK. Central to this position was the construction of the system as essentially a simple solution that would be straightforward to implement, and that it would allow 'us' to 'take back control'; 2) It was used in order to anticipate and rebut criticisms that the policy was anti-immigrant, racist, xenophobic, or otherwise based on prejudiced sentiment of some kind. These findings will be outlined in turn.

\section{A simple system to 'take back control'}

The Australian-style points system was offered as a straightforward solution to an urgent problem that required fixing. As an 'off the shelf' approach to managing the immigration system, the policy could be introduced as an obvious and easy-to-implement policy. For example, in extract 1, Nigel Farage is making his opening 'pitch' in one of the official leaders' debates: 


\section{Extract 1: BBC Election Debate, $16^{\text {th }}$ April 2015}

1 (.h) this general election

2 has become farcical (.)

3 every morning (.h) billions

4 of pounds being offered (.)

5 showered around like confetti

6 (.h) they're trying to bribe

7 you (.h) with borrowed money

8 (.h) now UKIP $(. h)$ has come

9 up (.) with a fully costed

10 (.) verified plan (.h) that

11 shows (.) we can cut the

12 taxes (.h) of working people

13 in this country (.h) to bring

14 about real economic

15 prosperity (.) and we do it

16 (.h) by cutting the bloated

17 overseas foreign aid budget

18 (.h) our contributions (.h)

19 to the European Union (.h)

20 let's take back control of

21 our country (.) take back

22 control of our borders (.h)

23 put in place (.h) an

24 Australian style points

25 system to control

26 immigration (.h) and take

27 on the big corporate giants

28 (.h) who've driven down

29 salaries (.h) and made life

30 so difficult (.h) for our 


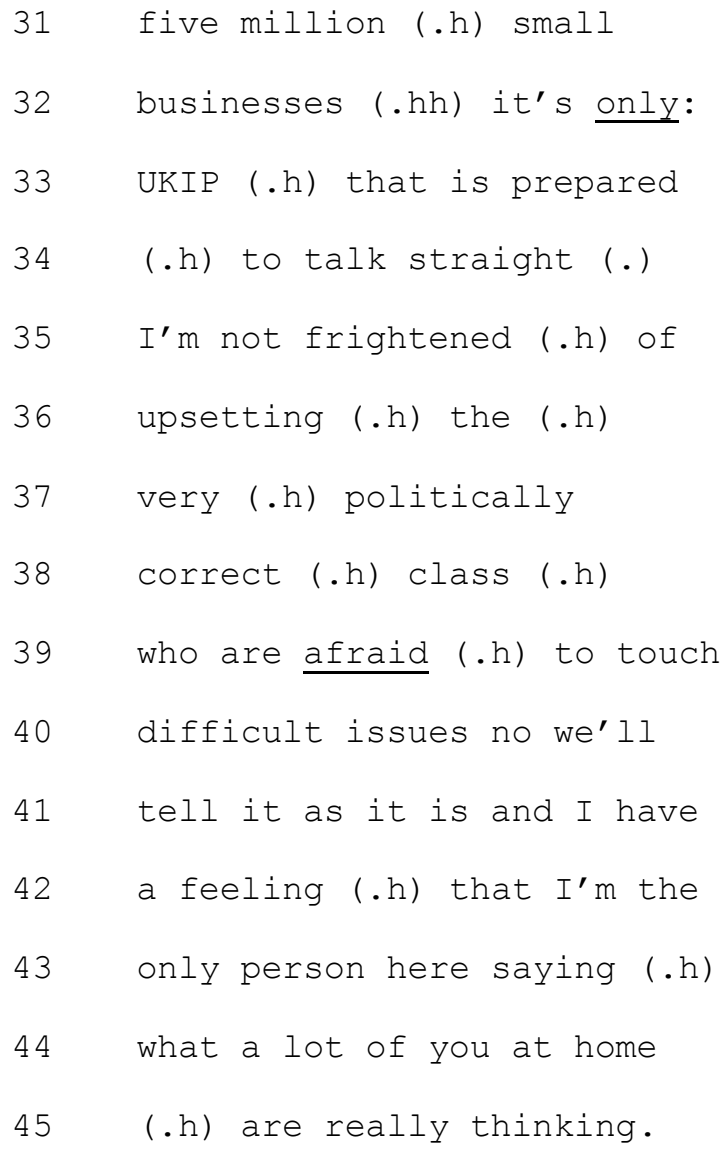

Farage's pitch features many of the rhetorical strategies adopted by UKIP in the campaign, and in this respect we can see how the invocation of the points system functions as part of a broader strategy of positioning UKIP as an insurgent party that is willing to say and do the difficult things that other parties are 'afraid' of. Farage achieves this through the construction of two intergroup contrasts. First, through a series of implicit contrasts, he distinguishes the unnamed ingroup of 'our country' from 'the European Union' (line 19), those in receipt of 'foreign aid' (line 17) and those who may seek to immigrate to 'our country' (lines 20-26). The banality (Billig, 1995) of the phrase 'our country' belies some taken for granted assumptions concerning the unifying features of the unspecified ingroup in the deictical referent our. By using the geographical referent 'country', Farage avoids the implication that anything other than shared territory unites 'us' (Abell, Condor \& Stevenson, 2006). The everyday nature of the phrase perhaps obscures this, but this is arguably a marker of the 
extent to which the ideological work it performs has become a part of commonsense.

Consider, for example, the implications that an alternative phrase, such as 'our nation', may have carried. Similarly, no outgroups are explicitly named in the building of these contrasts terms such as 'foreigners', 'immigrants' and 'Europeans' are absent.

Second, Farage builds a contrast between UKIP and mainstream political parties. Unlike in the first contrast, however, here he is more explicit in identifying the relevant groups, and in attributing certain qualities to them. Initially, UKIP's political opponents are referred to simply as 'they' (line 6), and are positioned as wilfully engaged in a transparent and irresponsible attempt 'to bribe you' (lines 6-7). The 'farcical' nature of this scenario is worked up through the extreme case formulation (ECF) 'every morning' on line 3 (Pomerantz, 1986), as well as through the simile of 'billions of pounds' being 'showered around like confetti' (line 5), and the description of this money as 'borrowed' (line 7). The implication is that 'they' are carelessly and indiscriminately making cynical claims about public spending that would lead to further debt. In contrast, UKIP's policies are constructed as rational (line 9: 'fully costed') and externally 'verified' (line 10). It is as part of this plan that the 'Australian style points system' is invoked on lines 24-25. The bureaucratized language of a 'points system' functions to convey objectivity and rationality, and in doing so allows for the claim to 'take back control of our borders ... to control immigration' to be proffered without explicit rejection of any particular outgroup. Farage subsequently moves on to attribute blame for falling wages not to immigrants, but to the 'big corporate giants' (line 27), and in doing so also aligns himself with 'our five million small businesses' (lines 30-32), before concluding by returning to the explicit contrast between UKIP and its opponents, who are now explicitly glossed as the 'very politically correct class' (lines 37-38). In doing so, he presents UKIP as the only party prepared to 'talk straight', and himself as 'not frightened of upsetting' (35-36) those opponents who 'are afraid to touch difficult issues' 
(lines 39-40). In contrast, 'we'll tell it as it is' (lines 40-41), and here it is clear that we refers to UKIP.

In carefully building these contrasts, Farage draws together the interests of 'our country', of 'working people' and 'small businesses', and presents UKIP - and himself personally - as being on their side. This is contrasted with 'the very politically correct class', who by implication are more concerned with the EU, 'foreign aid' and immigrants, as well as being aligned with 'big corporate giants'. In this context, Farage concludes by aligning himself explicitly with a majority of viewers, suggesting that he is saying what 'a lot of you at home are really thinking' (lines 42-45). The use of 'really' here is particularly noteworthy as it implies that people may be unwilling to say what they think. This accords with the previous invocations of fear and political correctness, and reflects a well-worn strategy on the part of UKIP for suggesting that mainstream politicians, as well as members of the public, have avoided overt discussion of immigration out of fear of the potential of being accused of racism. Much of this is left largely implicit in Farage's argument, but on other occasions speakers could spell out these underlying assumptions more explicitly. In particular, the points system could be used to anticipate and manage accusations of racism, xenophobia or otherwise exclusionary sentiment.

\section{Anticipating and rebutting accusations of racism}

Having set out how the points system was invoked as part of UKIP's general populist anti-establishment position, we will now move on to consider how the points system could be used to anticipate and manage accusations of racism. In extract 2, we can see how the invocation of the policy could be adorned with additional disclaimers and appeals to normative moral values in order to ward off potential inferences concerning racism, 
xenophobia, or a more general lack of humanitarian concern. The extract begins with the chair, David Dimbleby, posing a question to UKIP's Mark Reckless:

Extract 2: Question Time, 26 ${ }^{\text {th }}$ February 2015

\begin{tabular}{|c|c|}
\hline $\mathrm{DD}$ & =quite a lot of this \\
\hline & immigration is coming \\
\hline & from outside the EU \\
\hline & isn't it (.) so even \\
\hline & if you (.) had your \\
\hline & dream and we pulled \\
\hline & out of the European \\
\hline & Union you'd still have \\
\hline & people coming in $\downarrow$ \\
\hline MR & well what we do what \\
\hline & we want is a- an \\
\hline & Australian style \\
\hline & points based system \\
\hline & where we assess people \\
\hline & on the basis of skills \\
\hline & the likely contribution \\
\hline & they're going to make \\
\hline & to our $(. h)$ our- our \\
\hline & country we'll take our \\
\hline & our fair share of \\
\hline & genuine refugees as \\
\hline & well $\uparrow($.$) but we- we'd$ \\
\hline & set each year (.) what \\
\hline & that limit is (.) on \\
\hline & the basis of ski:lls \\
\hline & and we would apply it \\
\hline
\end{tabular}




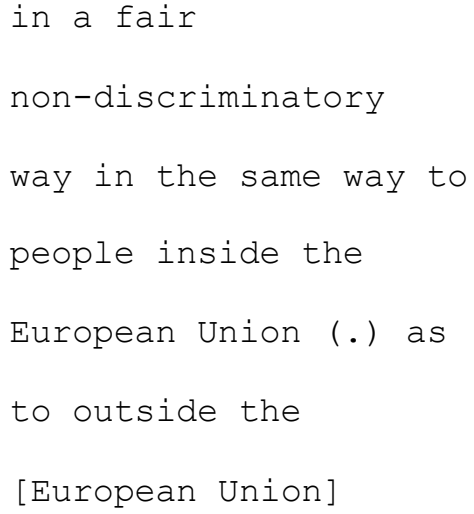

In this extract, there is no overt accusation of discrimination, but rather Reckless himself orients to the potential for arguments concerning limits on immigration to be heard as discriminatory. In anticipating this counter-argument, the neutrality and fairness of the Australian-style points system is worked up to argue that the key issue is one of the skills that would-be immigrants possess. Dimbleby's question functions to challenge the UKIP line on immigration by suggesting that withdrawal from the EU would be unlikely to reduce immigration. In response, Reckless invokes the 'Australian style points based system' in order to counter this suggestion. In spelling out the underlying principles, Reckless constructs the system as one that will assess each individual would-be immigrant on their merits (lines 14-19). Two features of this formulation are worthy of particular note: First, Reckless uses the psychological term skills to imply that people will have fixed and preexisting qualities that will make them either more or less desirable to 'our country'. This enables Reckless to frame the decision over whether or not someone will be allowed to enter the UK at an individual level. Second, the focus on the contribution of immigrants implies that immigration is to be valued only for the extent to which those coming in can benefit 'our country' (rather, than, for example, the other way round).

In an initial attempt to anticipate that this may be received as an inhumane or unjust system, Reckless states that 'we'll take our fair share of genuine refugees as well' (lines 1922), but in doing so introduces two important - but implicit - qualifications into his position. 
First, the reference to taking 'our fair share' implies that it is possible for there to be a share of refugees that would be unfair to us. Humanitarianism is thus tempered with a tacit assertion of the reciprocal nature of any such arrangement: we will provide refuge, but in so doing do not ourselves expect to be treated unfairly. In appealing to commonsense values of fairness, this also implies that other states may not be taking their 'fair share' of refugees. Second, his specification that genuine refugees will be taken implies that there may also be refugees who are not genuine. This formulation echoes longstanding distinctions between 'genuine' and 'bogus' refugees or asylum seekers in British political and media discourse (e.g. Lynn \& Lea, 2003).

If Reckless's invocation of refugees seems initially to involve a clear distinction between immigration and refuge, he subsequently goes on seemingly to conflate the two. $\mathrm{He}$ states that 'we'd set each year what that limit is', and at this point he appears to be referring to the limits that constitute the 'fair share' of refugees that he has just mentioned. However, he then states that the limit will be determined 'on the basis of skills' (lines 24-25). This seeming elision of the points-based system with the setting of the criteria for a 'fair share' of refugees reproduces a well-worn conflation of migration and the refuge/asylum system (Goodman \& Speer, 2007). Subsequently, he makes a further appeal to norms of fairness in explicitly stating that the criteria around the assessment of skills would be applied 'in a fair non-discriminatory way (lines 27-29), and specifies that this would apply to people from within, as well as outside, the EU. Not only does this manage the impression of the points system by constructing its non-discriminatory nature, but it also makes available the inference that at present such criteria are not applied fairly and that the current system is thus itself discriminatory. This frames the policy as the replacement of a currently discriminatory system with a fairer system that will not discriminate between EU and non-EU citizens. 
Extract 2 shows a speaker anticipating potential challenges to UKIP's policy, and seeking not only to address these but to position the present system as itself discriminatory, with the points system as a fairer alternative. On other occasions, the points system could be invoked by UKIP speakers when faced with a direct challenge concerning these aspects of their position. In extract 4, we see an example featuring UKIP politician Douglas Carswell responding to criticism from the Scottish National Party's Angus Robertson. In the build up to the stretch of debate presented in the extract, the panel members had been debating National Health Service (NHS) policy, and as we join the debate Robertson challenges Carswell by making a point concerning the importance of migrant labour in the NHS:

Extract 3: Question Time, 16 ${ }^{\text {th }}$ April 2015

\begin{tabular}{|c|c|c|}
\hline 1 & AR & Douglas (.) there's \\
\hline 2 & & an important (.) \\
\hline 3 & & there's an im- (.) \\
\hline 4 & & there's an important \\
\hline 5 & & thing to recognise in \\
\hline 6 & & the NHS (.) which is \\
\hline 7 & & that there's a very \\
\hline 8 & & high percentage (.) \\
\hline 9 & & of staff (.h) working \\
\hline 10 & & (.) from: (.) er the \\
\hline 11 & & wards (.) right up (.) \\
\hline 12 & & to the $r-$ consultant \\
\hline 13 & & level [who have come \\
\hline 4 & & from (.) other \\
\hline 5 & & countries] \\
\hline 16 & DC & {$\left[{ }^{\circ}\right.$ can I- (.) David can } \\
\hline & & I (.) come back on \\
\hline
\end{tabular}


AR

(.h) and (.) we owe

(.) a huge debt of

>gratitude< to them

(.) as we do to everybody else in the NHS (.h) how can you $\underline{\text { possibly say that your }}$ plans are gonna (.) m-

(.) be beneficial to $>$ the NHS $<($. h) when you're wanting to send people away from this [country]

AR

these are not

one [of- one of- one

of- one of=]

AR

[they are not

compatible]

DC

=the reasons:

44

DD

v- very [briefly would]

47 DC [o- one- (.) one of the reasons] why we 


$\begin{array}{ll}49 & \text { need an (.) Australian } \\ 50 & \text { points based system is } \\ 51 & \text { precisely so we can (.) } \\ 52 & \text { allow people to come } \\ 53 & \text { here with- the skills } \\ 54 & \text { we need (.) and one of } \\ 55 & \text { the skils we desperately } \\ 56 & \text { need (.) are people } \\ 57 & \text { with (.h) er (.) GP } \\ 58 & \text { qualifications (.) and } \\ 59 & \text { people who can work in } \\ 60 & \text { the NHS. }\end{array}$

Robertson constructs an inconsistency in Carswell's (and UKIP's) position by suggesting that UKIP's plan will not benefit the NHS because of the party's immigration policy, which is glossed as 'wanting to send people away from this country' (lines 29-31). In subsequently describing UKIP's position on immigration as 'not compatible' (lines 37-38) with trying to benefit the NHS, Robertson not only positions UKIP as pursuing an immigration policy that would be detrimental to the NHS, but also accuses the party of irrationality insofar as it pursues policies that are fundamentally incompatible.

To counter this accusation, Carswell invokes the points system (lines 49-50). By using the phrase 'precisely so' (line 51), he undermines Robertson's argument by suggesting that, rather than being a weakness of UKIP's policy, protection of the NHS is one of the specific reasons why the points system is needed. Rather than being indicative of "wanting to send people away', Carswell frames the policy as one that will 'allow people to come here' (lines 52-53). As in extract 2 above, Carswell uses the language of 'skills' asserting that people who have 'the skills we need' (lines 53-54) will be able to immigrate. Again, this 
prioritises the needs of the ingroup (we), over the needs of outgroups, and he asserts that skills for working in the NHS are a particular priority (lines 55-56: 'we desperately need'). Thus, the importance of prioritising the NHS is recognised, and in this respect the mobilisation of the points system works to position UKIP as pragmatic rather than dogmatic: the party is not opposed to immigration, but will seek to use a rational system for identifying where immigration is needed. The points system can thus be used specifically to counter an accusation that UKIP's policy is incompatible, incoherent and irrational.

The final extract features an example of some of the assumptions underpinning the points system being made explicit, and perhaps unusually it comes in the context of an admission of bias. The extract is taken from a series of special programmes under the BBC's Newsnight strand, entitled The Leader Interviews, and features the presenter, Evan Davis, interviewing UKIP leader Nigel Farage:

Extract 4: The Leader Interviews, 22 ${ }^{\text {nd }}$ April 2015

\begin{tabular}{|c|c|c|}
\hline 1 & $\mathrm{ED}$ & do you favour some \\
\hline 2 & & immigrants (.) let's \\
\hline 3 & & suppose one from \\
\hline 4 & & Mogadishu (.h) with \\
\hline 5 & & the same skills (.) \\
\hline 6 & & the same ability to \\
\hline 7 & & speak English but not \\
\hline 8 & & as a first language \\
\hline 9 & & from one from Melbourne \\
\hline 10 & & $(. h) \quad[$ are you- $]$ \\
\hline 11 & $\mathrm{NF}$ & I do] have \\
\hline 12 & & [a slight \\
\hline 13 & $\mathrm{ED}$ & [>do you< have a ] \\
\hline 1 & & preference \\
\hline
\end{tabular}


[ $>$ do you $<$ have ]

$\mathrm{NF} \quad[(. h) \mathrm{I}-\quad]$

ED a preference

NF I have to confess (.)

I do have a slight

preference $\uparrow$ (.h) I do:

(.h) think (.) naturally

(.h) that people from

India $\uparrow$ (.h) and Australia

(.h) are in some ways

(.) more likely (.h) to

speak English (.h)

understand common law

(.h) and have a

connection with (.h)

this country $(. h)$ er

than some people that

come (.h) perhaps from

countries (.h) that

haven't fully recovered

(.h) from being behind

the iron curtain (.)

>but $(. h)$ but $(. h)<$

but that's irrelevant

(.h) when you have an

Australian style points

system what you do (.h)

is you take out of that

(.h) all subjectivity

(.h) and you look at

things on a purely (.h) 


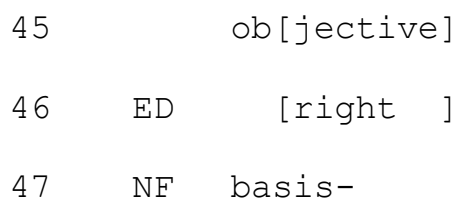

Farage's apparent admission of bias may in some respects be an unusual move, but before analysing this in detail it is worth noting that Davis's questions features the indirectness that is typical of anything that might be received as an accusation of racism (Augoustinos \& Every, 2010). Notably, Davis does not use terms such as 'bias' or 'prejudice' in his question, but simply asks 'do you favour' (line 1), or 'have a preference' for (lines 13-14), some groups over others.

In response, over lines 18-36 Farage acknowledges that he does have a 'slight preference' (lines 19-20) and goes on to explain why. In general terms, it might appear somewhat surprising that a politician would make such a statement of bias in as public a context as a broadcast media interview, but detailed consideration of how he formulates his 'slight preference' points to a number of ways in which he carefully manages this so as not to appear too irrational or prejudiced. First, his initial statement that he has a 'slight preference' (lines 18-20) is carefully constructed to manage his accountability. He frames his view as something that he has 'to confess', thereby orienting to its non-normative status; moreover the notion of compulsion mobilised in the phrase 'I have to' frames his confession as something that he has no control over, and which is thus beyond personal choice. In the subsequent formulation 'I do have a slight preference' (lines 19-20), it is notable that his use of the noun form (preference) rather than the verb (prefer), coupled with the phrase 'I do have', constructs his preference as something that he possesses, but which is nevertheless external to him. A hypothetical alternative phrase such as 'I do slightly prefer' would not have carried this same distance between himself and the preference. Similarly, the term 'preference' itself is noticeably less value-loaded than alternatives such as bias, favouritism, 
or prejudice. Finally, the claim that the preference is but a 'slight' one functions to enable it to be articulated, while nevertheless working to ensure that it is not seen as an overwhelmingly irrational, unreasonable one. While clearly orienting to the accountability of his view, this formulation nevertheless works to subtly mitigate his responsibility for it.

The way in which he subsequently proceeds to warrant his 'slight preference' is similarly notable for the way in which it is put together. When he specifies the objects of his preference he refers to 'people from India and Australia' (lines 22-23). The specification of India in particular is important here in working to resist the implication that his preference may be indicative of racism. While there is no outright denial of racism involved, the status of this formulation as working to anticipate and undermine potential inferences of racist sentiment depends upon tacit knowledge. Specifically, Farage's preference involves people from India, a country with a majority non-white population, just as much as it also takes in Australia, with a majority white population. Farage does not need to spell this out explicitly, although it remains available for more direct articulation should his questioner make an accusation of racism. It is also notable that rather than describing those who he prefers as Indians and Australians, he use the phrase 'people from India and Australia'. As in extract 1 above, this constructs group membership as secondary to geographical provenance, and thus similarly works subtly to undermine the potential inference that it is group membership per se that is the basis of his preference. His reasons for preferring these people are hedged (lines 24-25: 'in some ways more likely to'), thus avoiding the implication that he is making absolute claims, which again functions to work against the implication that he may be unreasonably prejudiced. Over lines 25-30, Farage outlines the specific reasons for his preference in the form of a three-part list (Jefferson, 1990) by suggesting that people from these countries are more likely (1) ‘to speak English'; (2) to 'understand common law'; and (3) to 'have a connection with this country'. Each of these reasons constitutes an oblique 
reference to historical ties between the UK and India and Australia, specifically those based around the legacy of the British Empire and the Commonwealth of Nations. This enables Farage to construct an essential cultural compatibility between Commonwealth nations and the UK without having to specify it as such, and in particular he goes on to contrast this with 'countries that haven't fully recovered from being behind the iron curtain' (lines 33-36), implying that it is immigration from eastern Europe that is the problem, and that it is a problem on cultural grounds insofar as people from eastern Europe may be less familiar with the linguistic and legal norms of the UK, as well as lacking some non-specific 'connection' with it.

Having gone to such lengths to construct himself both as having a 'slight preference', but also as not viewing some groups so unreasonably preferentially as to risk appearing to be egregiously biased or prejudiced, Farage then invokes the points system. He does this by dismissing his own previously stated preference as 'irrelevant' because the points system removes 'all subjectivity' to ensure that immigration decisions are made 'on a purely objective basis' (lines 43-47). The ECFs (all; purely) are notable here in that they make it clear that UKIP's system will be completely unbiased. In this context it is worth considering the function of Farage's preceding 'confession' of a 'slight preference'. While it might seem dangerous for a politician to admit to such preferences, even if they are managed carefully to mitigate their seriousness and any implication that they may be indicative of irrationality on the speaker's part, here the confession functions to highlight the virtues of a points system that is neutral and free from bias. In admitting to a 'slight preference', but in then advocating a system that works to ensure nobody receives unfair preferential treatment, Farage is effectively anticipating and countering any suggestion that he may be guilty of more serious biases. It enables him to present himself as enlightened and aware of his own potential for bias, and by extension the potential for bias in others, and in so doing makes available the 
inference that if he really were racist, xenophobic or otherwise motivated by prejudicial sentiment, he wouldn't be advocating a fair and objective system.

\section{Discussion}

The present paper has shown how UKIP's policy of introducing an 'Australian-style points based system' for immigration was used rhetorically in the context of broadcast media debates during the 2015 UK General Election campaign. The analysis highlights how a number of well-established discursive devices and rhetorical strategies for talking about immigrants and immigration are apparent in these data. However, these are joined here by a novel strategy which functions to obviate any imputation that UKIP's policy may be racist, xenophobic or otherwise discriminatory by seeking to individualize and psychologize immigration. In broad terms, this can be seen as an example of the way in which liberal arguments can be used for illiberal ends (Augoustinos \& Every, 2007). The emphasis on values of individualism and rationalism is a key feature of work on new racism, and these tropes are in evidence in the way in which the points system is mobilised in the present analysis. However, whereas previous work has focussed on how outgroups are constructed in a negative light, here the points system is used precisely to buttress against any implication that immigration policy is based on negative views of outgroups. The points system is presented as a simple administrative procedure that pays no attention to group membership and will instead assess individuals on their own merits. As such, it is constructed as a neutral technical process that removes any possibility of bias or subjectivity from the immigration system. This essentially involves a bureaucratization and individualization of the way in which immigration is constructed, which in many respects functions as arguably the most complete form of discursive deracialisation. Moreover, the policy is advocated not only on the grounds that it is itself non-discriminatory, but that the present system is discriminatory. 
This means that detailed analytic work is required to trace the ideological implications of arguments for the limitation of immigration that are based around the points system policy. Three issues in particular are pertinent here: 1) The assumptions undergirding the allocation of points based on individual 'skills';2) The construction of the policy as one based on a specifically Australian system; 3) The use of deictical referents (us, our, etc.) to construct implicit intergroup contrasts.

1) The psychologising of immigration discourse around the concept of skills is particularly notable. Not only is the Australian-style points system presented as a fair, rational and non-racist policy, but it is done so by focussing on the individual psychological qualities of immigrants. 'Skills' here are understood as psychological capacities that are possessed by individuals, and that exist - and can therefore be assessed - objectively and independently. These individual-level skills are implicitly treated as universal and acultural people from any part of the world will be assessed on the basis of their skills - and indeed this is part of the rhetorical value of the formulation. If skills were to be conceived of in rather different terms, for example as products of the interaction between individuals and socio-cultural context, this would mean that people from different parts of the world may be more likely to have certain 'skills' than people from other parts of the world. Such a construction would be less useful for UKIP speakers as it would imply that as cultural difference increases, so the likelihood of possessing 'skills' necessary for the UK economy also decreases. However, assuming a universal in-principle transferability of skills obscures culture and treats any failure to score enough 'points' as simply an individual factor. In this respect, the use of the points system - with its neutral-technical emphasis on quantifiable individual-level psychological capacities - accords with the tropes of neoliberal ideology, and can be identified as underpinning a number of more technocratic approaches to immigration policy in western states (Walsh, 2011). 
2) The specification of UKIP's immigration policy as involving a specifically Australian-style points system is notable in that it involves an appeal to a tacit representation of Australian immigration policy which treats it as a successful model that the UK should follow. In this respect, the policy involves not simply the advocacy of an abstract bureaucratic procedure, but an attempt to rhetorically anchor (Billig, 1991) the policy to the Australian immigration system. In constructing the system as already being in use elsewhere in the world, this functions rhetorically to anticipate any claims that the policy might be unworkable. However, this specifying of Australia also involves a lack of specificity insofar as it removes the policy from the particular historical process through which the Australian immigration system has been developed (see Hugo, 2014, for an overview). In the same way that 'skills' are treated as acultural universals, the points system is also treated as involving a simple 'off the shelf' technical procedure that can be taken from one cultural context and applied in another. In this respect, speakers draw on a decontextualized version of the Australian immigration system that removes it from the deeply contested historical and political context of Australian race relations (Tuffin, 2008), and neglects the related but distinct colonial histories of the UK and Australia.

3) Billig (1995) drew attention to the importance of deictical referents - 'little words' such as us, them, here, this, our, and so on, that flag the 'national' group and/or the 'national' homeland. This allows for a national frame of reference to be invoked in all sorts of contexts in which matters of nationalism may not be immediately or obviously apparent, such as when 'the weather' refers to the weather in a particular state.

The present dataset constitutes a prime example of the way in which the world of borders, states and 'national' populations is taken for granted in political discourse. It is underpinned by assumptions concerning who has the right to determine movement across borders ('take back control of our borders'), who particular territories belong to ('our 
country'), what group's priorities should drive immigration policy ('the skills we need'), and who has the right to make judgements concerning how immigrants meet these priorities ('we assess people'). Fundamentally this relies on the assumption that there is a meaningful distinction between an ingroup (us) and an outgroup. Notably, however, deictical referents for outgroups (e.g. them; they) are largely absent from these data. Instead, we are contrasted with 'people' (e.g. extract 3, line 14; extract 4, line 52). This is vitally important for UKIP speakers' strategy of individualisation in order to avoid the impression of being concerned with particular outgroups. Thus there is no concrete 'them' contrasted with 'us'; rather, the sole unifying feature of the implicit outgroup is that they are not us. The fact that such arguments can be made at all reflects the extent to which speakers can take for granted a shared ingroup frame of reference that - while not relying on any common features by virtue of shared categorical membership (Condor, 2006) - nevertheless can be assumed to share the basic and powerful assumption that, whoever we are, we take priority in our country. 


\section{References}

Abell, J., Condor, S., \& Stevenson, C. (2006). "We are an island": Geographical imagery in accounts of citizenship, civil society, and national identity in Scotland and in England. Political Psychology, 27, 207-226. doi: 10.1111/j.1467-9221.2006.00003.x

Augoustinos, M., \& Every, D. (2007). The language of "race" and prejudice: A discourse of denial, reason, and liberal-practical politics. Journal of Language and Social Psychology, 26, 123-141. doi: 10.1177/0261927X07300075

Augoustinos, M., \& Every, D. (2010). Accusations and denials of racism: Manging moral accountability in public discourse. Discourse \& Society, 21, 251-256. doi: $10.1177 / 0957926509360650$

Billig, M. (1991). Ideology and opinions: Studies in rhetorical psychology. London: Sage. Billig, M. (1995). Banal nationalism. London: Sage.

Condor, S. (2006). Temporality and collectivity: Diversity, history and the rhetorical construction of national entitativity. British Journal of Social Psychology, 45, 657682. doi: $10.1348 / 014466605 \times 82341$

Cowley, P., \& Kavanagh, D. (2016). The British General Election of 2015. Basingstoke: Palgrave Macmillan.

Ford, R., \& Goodwin, M. (2014). Revolt on the right: Explaining supportfor the radical right in Britain. London: Routledge.

Goodman, S., \& Speer, S. A. (2007). Category use in the construction of asylum seekers. Critical Discourse Studies, 4, 165-185. doi: 10.1080/17405900701464832

Hugo, G. (2014). Change and continuity in Australian international migration policy. International Migration Review, 48, 868-890. doi: 10.1111/imre.12120

Hutchby, I., \& Wooffitt, R. (1998). Conversation analysis: Principles, practices and applications. Cambridge: Polity. 
Jefferson, G. (1990). List-construction as a task and resource. In G. Psathas (Ed.), Interaction competence (pp. 63-92). Lanham, MD: University Press of America.

Lynn, N., \& Lea, S. (2003). 'A phantom menace and the new Apartheid': The social construction of asylum-seekers in the United Kingdom. Discourse \& Society, 14, 425-452. doi: 10.1177/0957926503014004002

Pomerantz, A. (1986). Extreme case formulations. A way of legitimizing claims. Human Studies, 9, 219-229. doi: 10.1007/BF00148128

Potter, J. (2012). Discourse analysis and discursive psychology. In H. Cooper (Ed.), APA handbook of research methods in psychology(Vol. 2). Washington, DC: American Psychological Association.

Tuffin, K. (2008). Racist discourse in New Zealand and Australia: Reviewing the last 20 years. Social and Personality Psychology Compass, 2, 591-607. doi: 10.1111/j.17519004.2007.00071.x

United Kingdom Independence Party. (2015). Believe in Britain: UKIP manifesto 2015. Retrieved from https://d3n8a8pro7vhmx.cloudfront.net/ukipdev/pages/1103/attachments/original/142 9295050/UKIPManifesto2015.pdf?1429295050

Van Dijk, T. A. (1992). Discourse and the denial of racism. Discourse \& Society, 3, 87-118. doi: $10.1177 / 0957926592003001005$

Walsh, J. P. (2011). Quantifying citizens: Neoliberal restructuring and immigrant selection in Canada and Australia. Citizenship Studies, 15, 861-879. doi: $10.1080 / 13621025.2011 .600135$

Wetherell, M., \& Potter, J. (1992). Mapping the language of racism: Discourse and the legitimation of exploitation. Hemel Hempstead: Harvester Wheatsheaf. 
Appendix: Transcription conventions (adapted from Hutchby \& Wooffitt, 1998, pp. vi-vii)

(0.4) The number in parentheses indicates a timing to the nearest tenth of a second.

(.) A dot enclosed in parentheses indicates a pause in the talk of less than two-tenths of a second.

[ ] Square brackets between adjacent lines of concurrent speech indicate the onset and end of a spate of overlapping talk.

.hh A dot before an ' $h$ ' indicates speaker in-breath. The more h's, the longer the in-breath

(( )) A description enclosed in double parentheses indicates a non-verbal activity. For example, ((pointing)). Alternatively double parentheses may enclose the transcriber's comments on contextual or other features.

- $\quad$ A dash indicates the sharp cut-off of the prior word or sound.

: Colons indicate that the speaker has stretched the preceding sound. The more colons the greater the extent of stretching.

that Underlined fragments indicate speaker emphasis.

$\circ$ Degree signs are used to indicate that the talk they encompass is spoken noticeably quieter than the surrounding talk.

$>\quad$ 'More than' and 'less than' signs indicate that the talk they encompass was produced noticeably quicker than the surrounding talk.

$=\quad$ Equals signs indicate latching, in which one utterances leads immediately into the next.

$\uparrow \quad$ An up arrow indicates rising intonation. A down arrow indicates falling intonation. 